\title{
SOLUSI ANALITIK DAN NUMERIK SUATU PERSAMAAN GELOMBANG SATU DIMENSI
}

\author{
AGUNG ALVIAN NOOR, ARRIVAL RINCE PUTRI, MAHDHIVAN SYAFWAN \\ Program Studi S1 Matematika, \\ Fakultas Matematika dan Ilmu Pengetahuan Alam, Universitas Andalas, \\ Kampus UNAND Limau Manis Padang, Indonesia. \\ email : agungalviannoor@gmail.com
}

Diterima 29 November Direvisi 3 Desember 2019 Dipublikasikan 12 Januari 2020

\begin{abstract}
Abstrak. Persamaan gelombang merupakan salah satu persamaan diferensial yang merepresentasikan fenomena fisis yang terjadi dalam kehidupan sehari-hari. Pada penelitian ini dibahas persamaan gelombang homogen satu dimensi. Solusi analitik dari persamaan gelombang tersebut ditentukan dengan metoda karakteristik. Solusi analitik dikonfirmasi dengan solusi numerik yang menggunakan metode beda hingga beda pusat dengan skema eksplisit. Hasil yang diperoleh memperlihatkan bahwa solusi analitik mempunyai pola yang sama dengan solusi numerik.
\end{abstract}

Kata Kunci: Persamaan Gelombang, Solusi Analitik, Metode Karakteristik, Solusi Numerik, Metode Beda Hingga

\section{Pendahuluan}

Banyak hukum alam yang mendasari perubahan-perubahan di alam ini dinyatakan dalam bentuk persamaan yang memuat laju perubahan dari suatu kuantitas. Persamaan tersebut dikatakan sebagai persamaan diferensial. Fenomena-fenomena fisis dalam kehidupan sehari-hari dapat dimodelkan secara matematika yang disajikan ke dalam bentuk persamaan diferensial [2].

Salah satu masalah fisis yang sering dijumpai adalah masalah gelombang. Persamaan gelombang merupakan persamaan yang sangat penting dalam matematika terapan. Terdapat bermacam-macam masalah gelombang, salah satunya adalah masalah getaran dari dawai yang diregangkan. Masalah ini sering disebut dengan persamaan gelombang satu dimensi yang mengatur gerak seutas dawai yang bergetar. Metode yang biasa digunakan untuk menyelesaikan persamaan gelombang, antara lain pemisahan variabel, transformasi Laplace dan metode karakteristik yang menghasilkan solusi D'Alembert [4].

Persamaan diferensial secara umum dapat diselesaikan secara analitik, namun pada kenyataannya dalam beberapa kasus, menentukan solusi secara analitik merupakan hal yang cukup rumit dan membutuhkan waktu. Oleh karena itu, pendekatan secara numerik menjadi alternatif pilihan dalam menentukan solusi persamaan diferensial. Salah satu metode numerik untuk menyelesaikan persamaan diferensial par- 
2 Agung Alvian Noor dkk.

sial adalah metode beda hingga yang mempunyai tiga tipe, yaitu beda maju, beda mundur, dan beda pusat [7].

Berdasarkan diuraikan sebelumnya, maka dalam penelitian ini akan ditentukan solusi persamaan suatu gelombang satu dimensi secara analitik dengan metode karakteristik dan secara numerik dengan metode beda hinga, kemudian akan dibandingkan dari kedua solusi tersebut.

\section{Landasan Teori}

\subsection{Metode Karakteristik}

Persamaan diferensial orde dua dengan variabel tak bebas $u$ dan variabel bebas $x$ dan $y$, dapat ditulis sebagai

$$
A u_{x x}+B u_{x y}+C u_{y y}+D u_{x}+E u_{y}+F_{u}=G .
$$

Asumsikan bahwa fungsi $u$ dan koefisien-koefisiennya adalah kontinu dan dapat diturunkan dua kali pada beberapa domain di $R^{2}$. Klasifikasi persamaan diferensial parsial (2.1) berdasarkan ketentuan

(1) Jika $B^{2}-4 A C>0$, maka persamaan (2.1) adalah hiperbola.

(2) Jika $B^{2}-4 A C=0$, maka persamaan (2.1) adalah parabola.

(3) Jika $B^{2}-4 A C<0$, maka persamaan (2.1) adalah elips.

Klasifikasi persamaan diferensial parsial orde dua didasarkan pada kemungkinan mereduksi persamaan (2.1) dengan tranformasi koordinat ke dalam bentuk kanonik atau bentuk standar pada suatu titik. Metode karakteristik adalah salah satu metode yang digunakan untuk menentukan solusi analitik suatu persamaan diferensial parsial [4]. Metode ini merubah persamaan diferensial parsial ke dalam bentuk kanonik. Untuk mengubah persamaan (2.1) ke dalam bentuk kanonik, didefinisikan variabel bebas $\xi$ dan $\eta$, dimana

$$
\begin{gathered}
\xi=\xi(x, y), \\
\eta=\eta(x, y) .
\end{gathered}
$$

sehingga persamaan (2.1) berubah menjadi

$$
A^{*} u_{\xi \xi}+B^{*} u_{\xi \eta}+C^{*} u_{\eta \eta}+D^{*} u_{\xi}+E^{*} u_{\eta}+F^{*} u=G^{*},
$$

dimana

$$
\begin{aligned}
& A^{*}=A \xi_{x}^{2}+B \xi_{x} \xi_{y}+C \xi^{2} \\
& B^{*}=2 A \xi_{x} \eta_{x}+B\left(\xi_{x} \eta_{y}+\xi_{y} \eta_{x}\right)+2 C \xi_{y} \eta_{y} \\
& C^{*}=A \eta_{x}^{2}+B \eta_{x} \eta_{y}+C \eta_{y}^{2} \\
& D^{*}=A \xi_{x x}+B \xi_{x y}+C \xi_{y y}+D \xi_{x}+E \xi_{y} \\
& E^{*}=A \eta_{x x}+B \eta_{x y}+C \eta_{y y}+D \eta_{x}+E \eta_{y} \\
& F^{*}=F \\
& G^{*}=G .
\end{aligned}
$$

Persamaan (2.3) mempunyai bentuk yang sama dengan persamaan (2.1) dengan transformasi (2.2). 


\subsection{Metode Beda Hingga}

Metode beda hingga adalah metode yang biasa digunakan untuk menentukan aproksimasi persamaan diferensial parsial dengan bantuan komputasi. Metode ini menggunakan definisi turunan dan deret Taylor untuk menurunkan aproksimasi beda hingga turunan pertama dan kedua dari suatu fungsi [3]. Metode beda hingga bekerja dengan merubah daerah variabel bebas menjadi grid berhingga yang disebut mesh dimana variabel tak bebasnya diaproksimasi.

\subsection{Kestabilan Von Neumann}

Kestabilan Von-Neumann dapat digunakan untuk menganalisis kestabilan suatu persamaan beda hingga. Untuk menentukan syarat kestabilan, digunakan pendekatan

$$
u_{m}^{n}=\alpha^{n} e^{i \beta m} .
$$

Solusi numerik dengan metode beda hingga untuk persamaan gelombang satu dimensi akan stabil jika $\epsilon \leq 1[6]$.

\section{Pembahasan}

\subsection{Bentuk Umum Persamaan Gelombang Homogen Satu Dimensi}

Persamaan gelombang homogen satu dimensi yang akan ditentukan solusinya pada penelitian ini dinyatakan dalam bentuk

$$
\begin{aligned}
\frac{\partial^{2} u}{\partial t^{2}} & =c^{2} \frac{\partial^{2} u}{\partial x^{2}}, & -\infty<x<+\infty, t>0, \\
u(x, 0) & =f(x), & \\
u_{t}(x, 0) & =g(x), &
\end{aligned}
$$

dimana $c$ adalah konstanta positif.

\subsection{Solusi Analitik}

Persamaan (3.1) akan ditentukan solusi analitiknya dengan menggunakan metode karakteristik dengan langkah-langkah sebagai berikut :

(1) Memeriksa klasifikasi persamaan

Dari persamaan (3.1) diketahui bahwa

$$
-c^{2} \frac{\partial^{2} u}{\partial x^{2}}+\frac{\partial^{2} u}{\partial t^{2}}=0
$$

artinya dapat diidentifikasi bahwa persamaan (3.2) mempunyai nilai $A=-c^{2}$, $B=0$, dan $C=1$, sehingga diperoleh

$$
\begin{aligned}
B^{2}-4 A C & =0^{2}-(4)\left(-c^{2}\right)(1) \\
& =4 c^{2}>0 .
\end{aligned}
$$

Jadi persamaan (3.1) termasuk persamaan diferensial parsial tipe hiperbola. 
4 Agung Alvian Noor dkk.

(2) Menentukan persamaan karakteristik

Selanjutnya akan dicari persamaan karakteristik dari persamaan (3.1), dengan

$$
\frac{d t}{d x}=\frac{B \pm \sqrt{B^{2}-4 A C}}{2 A}
$$

Jadi persamaan karakteristik dari (3.1) adalah

$$
\begin{gathered}
\frac{d t}{d x}=-\frac{1}{c}, \\
\frac{d t}{d x}=\frac{1}{c} .
\end{gathered}
$$

(3) Menentukan kurva karakteristik

Selanjutnya integralkan persamaan (3.3) dan (3.4) agar diperoleh kurva karakteristiknya, yaitu

$$
\begin{aligned}
& C_{1}=x+c t, \\
& C_{2}=x-c t .
\end{aligned}
$$

(4) Mengubah persamaan ke dalam bentuk kanonik

Dari kurva karakteristik diubah ke bentuk kanonik, yaitu

$$
\begin{aligned}
& \xi=x+c t \\
& \eta=x-c t .
\end{aligned}
$$

Matriks Jacobian dari persamaan (3.5) adalah

$$
J=\left|\begin{array}{cc}
1 & c \\
1 & -c .
\end{array}\right|=-c-c=-2 c \neq 0,
$$

sehingga diperoleh

$$
\begin{gathered}
\frac{\partial^{2} u}{\partial x^{2}}=\frac{\partial^{2} u}{\partial \xi^{2}}+2 \frac{\partial^{2} u}{\partial \xi \partial \eta}+\frac{\partial^{2} u}{\partial \eta^{2}}, \\
\frac{\partial^{2} u}{\partial t^{2}}=c^{2} \frac{\partial^{2} u}{\partial \xi^{2}}-2 c^{2} \frac{\partial^{2} u}{\partial \xi \partial \eta}+c^{2} \frac{\partial^{2} u}{\partial \eta^{2}} .
\end{gathered}
$$

Selanjutnya substitusi persamaan (3.6) dan (3.6) ke persamaan (3.1), diperoleh

$$
-4 c^{2} \frac{\partial^{2} u}{\partial \xi \partial \eta}=0 .
$$

Jadi bentuk kanonik persamaan (3.1) adalah

$$
\frac{\partial^{2} u}{\partial \xi \partial \eta}=0
$$

(5) Menentukan solusi dari bentuk kanonik

Solusi dari persamaan (3.6)

$$
u(\xi, \eta)=F(\xi)+G(\eta),
$$


atau bisa ditulis kedalam bentuk

$$
u(x, t)=F(x+c t)+G(x-c t),
$$

dengan $F$ dan $G$ adalah sebarang fungsi yang dapat diturunkan.

Selanjutnya, jika diberikan syarat awal persamaan gelombang satu dimensi, yaitu

$$
u(x, 0)=f(x),
$$

maka diperoleh

$$
F(x)+G(x)=f(x),
$$

dan

$$
u_{t}(x, 0)=g(x)
$$

maka diperoleh

$$
\begin{aligned}
c F^{\prime}(x)-c G^{\prime}(x) & =g(x) \\
F(x)-G(x) & =\frac{1}{c} \int_{x_{0}}^{x} g(s) d s+C .
\end{aligned}
$$

Dari persamaan (3.7) dan (3.8) dapat dilakukan eliminasi dan subtitusi sehingga diperoleh

$$
\begin{gathered}
F(x)=\frac{1}{2 c}\left(\int_{x_{0}}^{x} g(s) d s+c f(x)+\frac{C}{2}\right), \\
G(x)=-\frac{1}{2 c}\left(\int_{x_{0}}^{x} g(s) d s-c f(x)+\frac{C}{2}\right) .
\end{gathered}
$$

Jadi solusi umum persamaan (3.1) adalah

$$
u(x, t)=\frac{1}{2}(f(x+c t)+f(x-c t))+\frac{1}{2 c} \int_{x-c t}^{x+c t} g(s) d s .
$$

\subsection{Solusi Numerik}

Skema numerik persamaan gelombang (3.1) dengan metode beda hingga pusat skema eksplisit, yaitu:

$$
\begin{aligned}
\frac{\partial^{2} u}{\partial t^{2}} & =c^{2} \frac{\partial^{2} u}{\partial x^{2}} \\
\frac{u_{i}^{j-1}+u_{i}^{j+1}-2 u_{i}^{j}}{\triangle t^{2}} & =c^{2} \frac{u_{i-1}^{j}+u_{i+1}^{j}-2 u_{i}^{j}}{\triangle x^{2}} .
\end{aligned}
$$

atau

$$
u_{i}^{j+1}=\epsilon^{2} u_{i+1}^{j}+2\left(1-\epsilon^{2}\right) u_{i}^{j}+\epsilon^{2} u_{i-1}^{j}-u_{i}^{j-1},
$$


6 Agung Alvian Noor dkk.

untuk $i=0,1,2,3, \ldots, m$ dan $j=1,2,3, \ldots, n$, untuk $j=0$

$$
u_{i}^{1}=\frac{1}{2} \epsilon^{2} u_{i+1}^{0}+\left(1-\epsilon^{2}\right) u_{i}^{0}+\frac{1}{2} \epsilon^{2} u_{i-1}^{0}+\triangle t\left(u_{t}\right)_{i}^{0},
$$

dengan $\epsilon=\frac{c \triangle t}{\triangle x}$

\subsection{Contoh Kasus Sebagai Perbandingan Solusi Analitik dan Numerik}

Diberikan persamaan gelombang homogen satu dimensi sebagai berikut

$$
\begin{array}{rlrl}
\frac{\partial^{2} u}{\partial t^{2}} & =c^{2} \frac{\partial^{2} u}{\partial x^{2}}, & -\infty<x<+\infty, t>0 \\
u(x, 0) & =\sin (x), & \\
u_{t}(x, 0) & =0 .
\end{array}
$$

Solusi umum persamaan (3.14) adalah

$$
u(x, t)=\frac{1}{2}(f(x+c t)+f(x-c t))+\frac{1}{2 c} \int_{x-c t}^{x+c t} g(s) d s .
$$

Jika disubstitusi syarat awal

$$
\begin{aligned}
u(x, 0) & =\sin (x)=f(x), \\
u_{t}(x, 0) & =0=g(x),
\end{aligned}
$$

ke dalam persamaan (3.14), maka diperoleh solusi khusus

$$
\begin{aligned}
u(x, t) & =\frac{1}{2}(\sin (x+c t)+\sin (x-c t))+\frac{1}{2 c} \int_{x-c t}^{x+c t} 0 d s \\
& =\frac{1}{2}(\sin (x+c t)+\sin (x-c t))+\frac{1}{2 c}(0) \\
& =\frac{1}{2}(\sin (x+c t)+\sin (x-c t)) \\
& =\sin (x) \cos (c t) .
\end{aligned}
$$

Solusi numerik persamaan gelombang (3.14) dengan metode beda hingga pusat skema eksplisit, yaitu:

$$
\begin{aligned}
\frac{\partial^{2} u}{\partial t^{2}} & =c^{2} \frac{\partial^{2} u}{\partial x^{2}} \\
\frac{u_{i}^{j-1}+u_{i}^{j+1}-2 u_{i}^{j}}{\triangle t^{2}} & =c^{2} \frac{u_{i-1}^{j}+u_{i+1}^{j}-2 u_{i}^{j}}{\triangle x^{2}}
\end{aligned}
$$

atau

$$
u_{i}^{j+1}=\epsilon^{2} u_{i+1}^{j}+2\left(1-\epsilon^{2}\right) u_{i}^{j}+\epsilon^{2} u_{i-1}^{j}-u_{i}^{j-1},
$$

untuk $i=0,1,2,3, \ldots, m$ dan $j=0,1,2,3, \ldots, n$, serta $\epsilon=\frac{c \triangle t}{\triangle x}$. 
Misalkan nilai $c=0.5, x$ dan $t$ masing-masing adalah $-10 \pi \leq x \leq 10 \pi$ dan $0 \leq t \leq 3$ pada saat $\triangle x=0.1$ dan $\triangle t=0.05$. Solusi analitik dan solusi numrik persamaan (3.14) dapat dilihat pada Gambar (1) dan Gambar (??). Pada Gambar (2) diberikan profil solusi analitik yang diperlihatkan oleh garis putus-putus berwarna biru dan solusi numerik yang diperlihatkan oleh garis berwarna hijau pada posisi $-10 \pi<x<10 \pi$ dengan $t=1,2,3$. Dari Gambar (2) dapat dilihat bahwa solusi analitik memiliki pola yang sama dengan solusi numerik dan solusi numerik selalu menghampiri solusi analitiknya. Nilai simpangan gelombang $u$ yang merupakan sumbu vertikal dari profil juga terus mengecil seiring dengan membesarnya $t$.

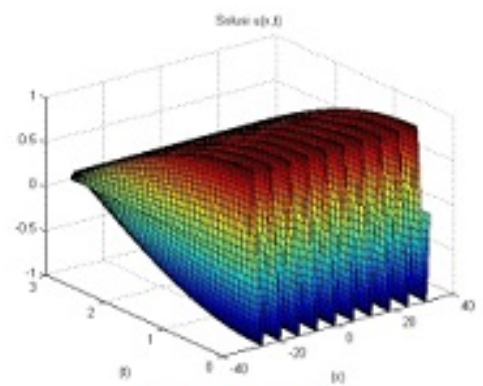

(a) Sohai analitik:

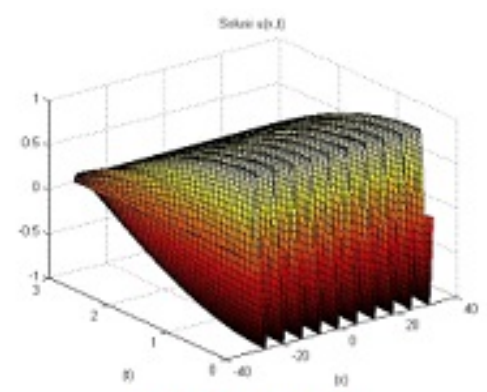

(b) Sohsi numeri:

Gambar 1. Grafik Solusi Persamaan (3.14)
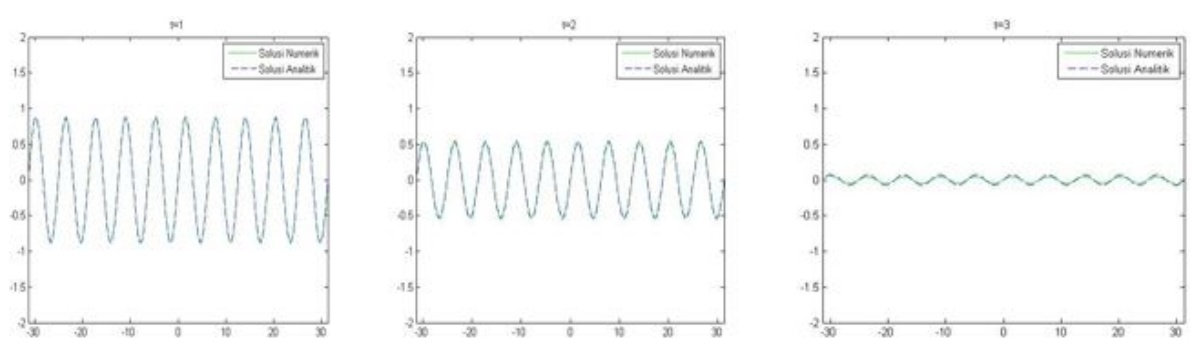

Gambar 2. Perbandingan Solusi Analitik dan Numerik untuk t=1,2,3.

\section{Kesimpulan}

(1) Solusi umum persamaan gelombang homogen satu dimensi secara analitik adalah

$$
u(x, t)=\frac{1}{2}(f(x+c t)+f(x-c t))+\frac{1}{2 c} \int_{x-c t}^{x+c t} g(s) d s .
$$


(2) Solusi numerik persamaan gelombang homogen satu dimensi didapat dengan menggunakan metode beda hingga pusat skema eksplisit, yaitu

$$
u_{i}^{j+1}=\epsilon^{2} u_{i+1}^{j}+2\left(1-\epsilon^{2}\right) u_{i}^{j}+\epsilon^{2} u_{i-1}^{j}-u_{i}^{j-1},
$$

untuk $i=0,1,2,3, \ldots, m$ dan $j=0,1,2,3, \ldots, n$, serta $\epsilon=\frac{c \triangle t}{\triangle x}$.

Pada $j=0$, dalam skema terdapat nilai $u_{i}^{-1}$ yang tidak diketahui, sehingga digunakan nilai $u_{t}(x, 0)=0$ awal untuk mencari nilai $u_{i}^{-1}$ sebagai berikut

$$
u_{i}^{1}=\frac{1}{2} \epsilon^{2} u_{i+1}^{0}+\left(1-\epsilon^{2}\right) u_{i}^{0}+\frac{1}{2} \epsilon^{2} u_{i-1}^{0}+\triangle t\left(u_{t}\right)_{i}^{0} .
$$

(3) Dengan metode Von Neumann dapat diketahui bahwa skema eksplisit beda pusat untuk persamaan gelombang homogen satu dimensi akan stabil jika $\epsilon^{2} \leq$ 1.

(4) Berdasarkan perbandingan solusi pada contoh dengan metode karakteristik dan metode beda hingga pusat skema eksplisit menghasilkan solusi numerik yang memiliki pola yang sama dan selalu menghampiri solusi analitik.

\section{Ucapan Terima kasih}

Penulis mengucapkan terima kasih kepada ibu Dr. Susila Bahri, bapak Dr. Admi Nazra, dan ibu Dr. Ferra Yanuar selaku dosen penguji tugas akhir yang telah memberikan masukkan dan saran sehingga makalah ini dapat diselesaikan dengan baik.

\section{Daftar Pustaka}

[1] Bronson, R., G. C., 1973, Persamaan Diferensial with Aplication, Edisi-3, Erlangga, Jakarta

[2] Boyce, W.E., Richard C. D., 2000, Elementary Differential Equation and Boundary Value Problems, Edition-7, John Wiley, New York

[3] Jakobsen, P.K, 2019, An Introduction to Partial Differential Equation, University of Norway, Tromso

[4] Myint-U, Tyn, dan L. D., 2007, Linear Partial Differensial Equations for Scientists and Engineers, Edition-4, University of Texas-Pan American, Edinburg

[5] Purcell, E. J., Dale V., dan Steven E, 2003. Kalkulus, Edisi Ke-8, Erlangga, Jakarta

[6] Zauderer, E, 2006, Partial Diferential Equation of Applied Mathematics, John Wiley, New York

[7] Zill, G. Dennis, dan M. R. Cullen, 1976, Differential Equation : With Boundary Value Problems Edition-7, Brooks-Cole, Kanada 